\title{
The Role of Exercises in Osteoporotic Fracture Prevention and Current Care Gaps. Where Are We Now? Recent Updates
}

\author{
Helen Senderovich, M.D., M.C.F.P., C.O.E., P.C. ${ }^{1 *}$, Henry Tang ${ }^{2}$, and Samuel \\ Belmont, B.M.Sc. ${ }^{2}$ \\ ${ }^{\prime}$ Geriatrics \& Palliative Care \& Pain Medicine, Baycrest Health Sciences, Assistant Professor, University \\ of Toronto, Department of Family and Community Medicine, Division of Palliative Care, Toronto, \\ Canada; and ${ }^{2}$ Baycrest Health Sciences, Toronto, Canada
}

\begin{abstract}
Introduction: The primary non-pharmacological management recommended for patients with osteoporosis (OP) is exercise, but whether it should be high-force, resistive, or other means can be obscure.

Objective: To describe the role of exercises in osteoporotic fracture prevention, identify effects and potential risks of high-force exercises, detect the optimal exercises to combat OP, and explore the challenges that might arise from interventions.

Methods: A search on MEDLINE and Cochrane databases was conducted on the role of exercises in preventing osteoporotic fractures from 1989 onwards, leading to 40 results, including op-ed pieces, qualitative studies, randomized clinical trials (RCTs) $(n=5)$, and RCT follow-up studies $(n=1)$. Articles deemed relevant to the objectives were analyzed and summarized. Data on effects of vitamin $D$ and calcium supplementation were later gathered from different sources as well.
\end{abstract}

\footnotetext{
Abbreviations: BMC, bone mineral content; BMD, bone mineral density; OP, osteoporosis; PSW, personal support worker; RCT, randomized control trial.

Citation: Senderovich H, Tang H, Belmont S. The Role of Exercises in Osteoporotic Fracture Prevention and Current Care Gaps. Where Are We Now? Recent Updates. Rambam Maimonides Med J 2017;8 (3):eoo32. Review. doi:10.5041/RMMJ.10308

Copyright: (C) 2017 Senderovich et al. This is an open-access article. All its content, except where otherwise noted, is distributed under the terms of the Creative Commons Attribution License (http://creativecommons.org/licenses/by/3.0), which permits unrestricted use, distribution, and reproduction in any medium, provided the original work is properly cited.

Conflict of interest: No potential conflict of interest relevant to this article was reported.

* To whom correspondence should be addressed. E-mail: hsenderovich@baycrest.org
} 
Results: High-intensity, resistive strength training provided the maximum benefit in increasing bone mineral density (BMD) levels, muscle mass, and reduction in fractures, while posture and balance exercises only improved mobility. High-force exercises did not increase fractures and were associated with increases in BMD. Interventions including exercises, vitamin D, and calcium intake had limited effect when used as single interventions, while vitamin $\mathrm{D}$ and calcium may potentially cause increases of cardiovascular events.

Conclusion: A long-term regular exercise program designed to improve postural stability, mobility, and mechanical efficiency, alongside an increased vitamin D and dietary calcium intake, is most effective in preventing $\mathrm{OP}$ and reducing osteoporotic fractures.

KEY WORDS: Bone mineral density, elderly, exercise, fracture, osteoporosis

\section{INTRODUCTION}

Osteoporosis (OP) is an incurable weakening of bone structure due to loss of tissue from mineral deficiency in the elderly. It is the most common type of bone disease, ${ }^{1}$ and the low bone mineral density (BMD) leads to an increased risk of skeletal fractures, most often in the hip, wrist, or vertebrae. Osteoporotic fractures are one of the leading causes of death in the elderly. ${ }^{2}$ Current treatment and management are limited and focused on regular screening and pharmacological interventions. However, non-pharmacological options including exercises cannot be overlooked and can be just as critical in maintaining bone health, although experts disagree on the most effective forms of exercise. Highforce training is effective in developing bone and muscle mass, but may increase risk of trauma, 3 while low-force training is safer but potentially lacks in terms of BMD growth. In this review, we concentrated on the role and difference in impact of highand low-force exercises on osteoporotic fractures. Vigorous, short, and repetitive doses of mechanical loads were found to reduce hip fracture risk, and increase BMD. 4 Resistance and balance training were associated with better mobility and may reduce falls and subsequently prevent fractures. 5 Moderateforce exercise, involving resistance and balance training, is recommended to the elderly and may reduce risk and fear of fractures, although its effectiveness is conditional.

Recent estimates state over 200 million people have OP, ${ }^{6}$ a number that is expected to increase in the following years. By 2050, hip fracture cases are estimated to increase by $310 \%$ and $240 \%$ in men and women, respectively, compared to rates in 1990.7 The greatest consequence of OP is an increased risk and fear of fractures: over 8.9 million fractures, which stem from falls to small stresses, are caused annually by this disease. 7
Unfortunately, OP produces no symptoms before fractures, making detection difficult. As of now there is no treatment, and the increasing prevalence of fractures makes diagnosis and the management of the disease all the more critical. Risk factors that may contribute to the development of OP include aging, weight lower than $60 \mathrm{~kg}$, family heredity, medication such as steroids, smoking, and becoming postmenopausal for women. However, regular screening and injury are the only ways accurately to diagnose the disease, both of which are tedious. By that point, OP could have progressed to a dangerous level, and the damage might have already become extraordinarily severe: disabilities caused by OP exceed those caused by all cancers except lung cancer. ${ }^{7}$ Although certain tests, such as a timed "up and go," have been shown to be a sensitive and accurate measure for recurring fractures, ${ }^{8}$ there have not been many experiments to definitely validate the procedure's effectiveness.

There is currently no treatment for OP, although pharmacological drugs such as bisphosphonate, estrogens, and parathyroid hormone (teriparatide) have been shown to be able to slow down or pause the breakdown of bone tissue, although not without side effects. 9 The non-pharmacological option of exercises is more often recommended as it can be more effective than drugs and is widely accessible. The best method of exercise, however, remains a debatable topic. Maintaining or increasing mobility, muscle strength, BMD, bone mineral content (BMC), and balance requires regular, moderate to vigorous, high-force exercise. It is also possible that such force and high-impact exercises may result in more falls and have similar effectiveness in increasing BMD as low-force and low-intensity training, 3 although evidence in this area appears to be lacking. The exact repertoire of exercise varies from person to person; nevertheless, this review will 
explore the general qualities required for all fracture-reducing exercises.

Our objective was to describe the effects and potential risks of high-force exercise, identify the optimal exercises to combat OP, and explore the challenges that might arise from the intervention.

\section{METHOD}

We conducted a MEDLINE as well as a Cochrane databases search on recent literature regarding the role of exercises in prevention of osteoporotic fractures to get this review started. We limited our search to the years from 1989 onwards. This yielded about 40 results ranging from op-ed pieces to qualitative studies, to randomized clinical trials (RCTs) $(n=5)$ and RCT follow-up studies $(n=1)$, to prospective cohort studies $(n=6)$, as well as crosssectional studies $(n=2)$ and non-randomized controlled clinical trials $(n=1)$. We identified relevant systematic reviews and meta-analyses $(n=7)$ from these databases and checked their reference lists, as well as the RCTs included in the review, to supplement the search. Of these, only approximately 16 were deemed to be useful and relevant to the objective at hand. These articles were then read and the relevant points and themes were summarized. Corroborative themes were identified, and the authors responsible for the contributing research were cited as they came up. Additional sources were added to the literature search after scrutinizing the papers' reference lists. Trials in which participants were not at risk of OP were excluded, as well as trials in which only high-trauma fractures were recorded as an outcome.

A summary of articles reviewed is found in Table 1.

\section{DISCUSSION}

\section{Effects of High-Force Exercise}

The immediate step to take for any individual desiring to strengthen bone health is to undergo regular vigorous exercise. Through extensive study, high-intensity exercise has been examined and found to produce several positive effects. Analysis has indicated that exercises may serve to maintain mobility, physicality, BMD, muscle, strength, and balance. ${ }^{22}$ One RCT found that high-intensity strength training, when employed twice a week, proved to be a feasible means to preserve bone density while improving muscle mass, strength, and balance in postmenopausal women. ${ }^{14}$ Together, these benefits attributed to a small but statistically significant reduction in falls, particularly when the exercise program involved balance and lower-body strength training, which may be associated with a reduction of up to $40 \%$ in hip fractures. ${ }^{21}$ In a metaanalysis of 13 cohort studies, with all participants over the age of 40 , moderate to vigorous exercise was found to reduce hip fractures by $45 \%$ and $38 \%$ in men and women, respectively. 3 The potential benefits of a low-intensity program were less pronounced, as they may initially fail to prevent bone loss and lead to increased fall risk, despite increased muscle strength. ${ }^{11,23}$ However, when examined at a 10-year long-term follow-up, there was evidence that a low-intensity program can indeed lead to a reduction in fractures. ${ }^{13}$

Despite concern from many osteoporotic patients that exercise increases the risk of fractures, data suggested that injury rates actually decline, ${ }^{1}$ and severe damage was non-existent. Several experiments in the past decade involving the elderly (mean age around 70) undergoing several months of exercise programs that featured balance, resistance, and walking showed improvements in maximum standing time, which may indicate lower risk of falls and subsequent fractures. Serious detrimental effects including new vertebral fractures or wavering cardiovascular systems were not found. ${ }^{24}$ The intensity could be considered moderate to intense, although no significant high-force exercise was practiced. For residents at high risk of fractures, balance, strength, and functional training exercises were suggested only as a part of a multifactorial intervention to prevent falls. Importantly, this recommendation was primarily focused upon avoiding the small increase in falls which may occur among high-risk individuals when participating in exercises. ${ }^{25}$

It should be noted that identifying patients at high risk of fracture does not necessarily require BMD testing. ${ }^{26}$ Patients who have had prior hip fracture or vertebral fracture, recently used systemic glucocorticoids and have had one prior fracture, or who have been identified as at high risk due to repeated falls, and/or are on OP treatment are all considered at high risk of fracture. ${ }^{26}$

Another benefit exercise had on patients with OP was a reduced fear of falling. A RCT involving 89 elderly women who undertook a 3-month exercise program revealed that patients with a history of osteoporotic fractures had significantly lowered risk 


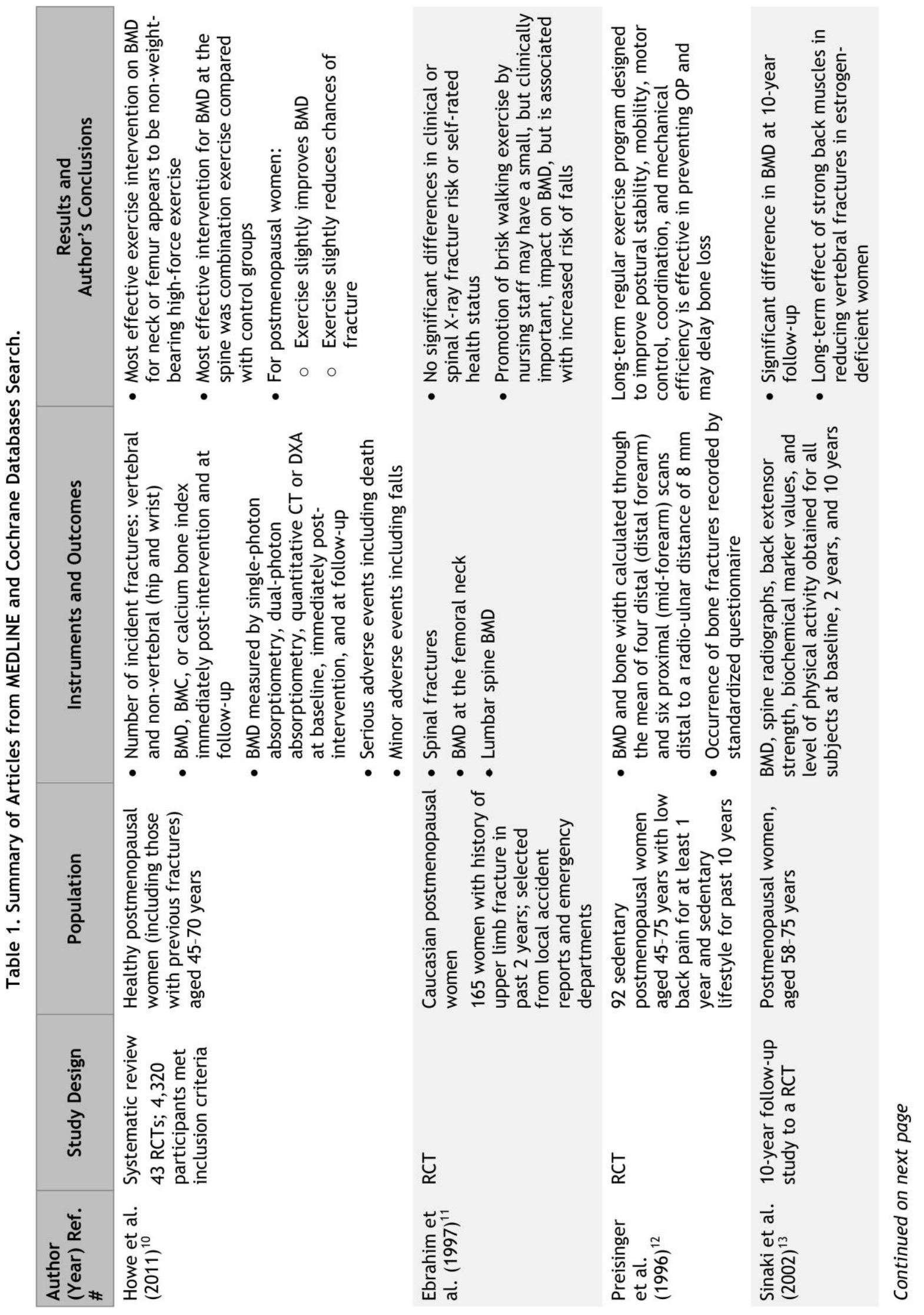




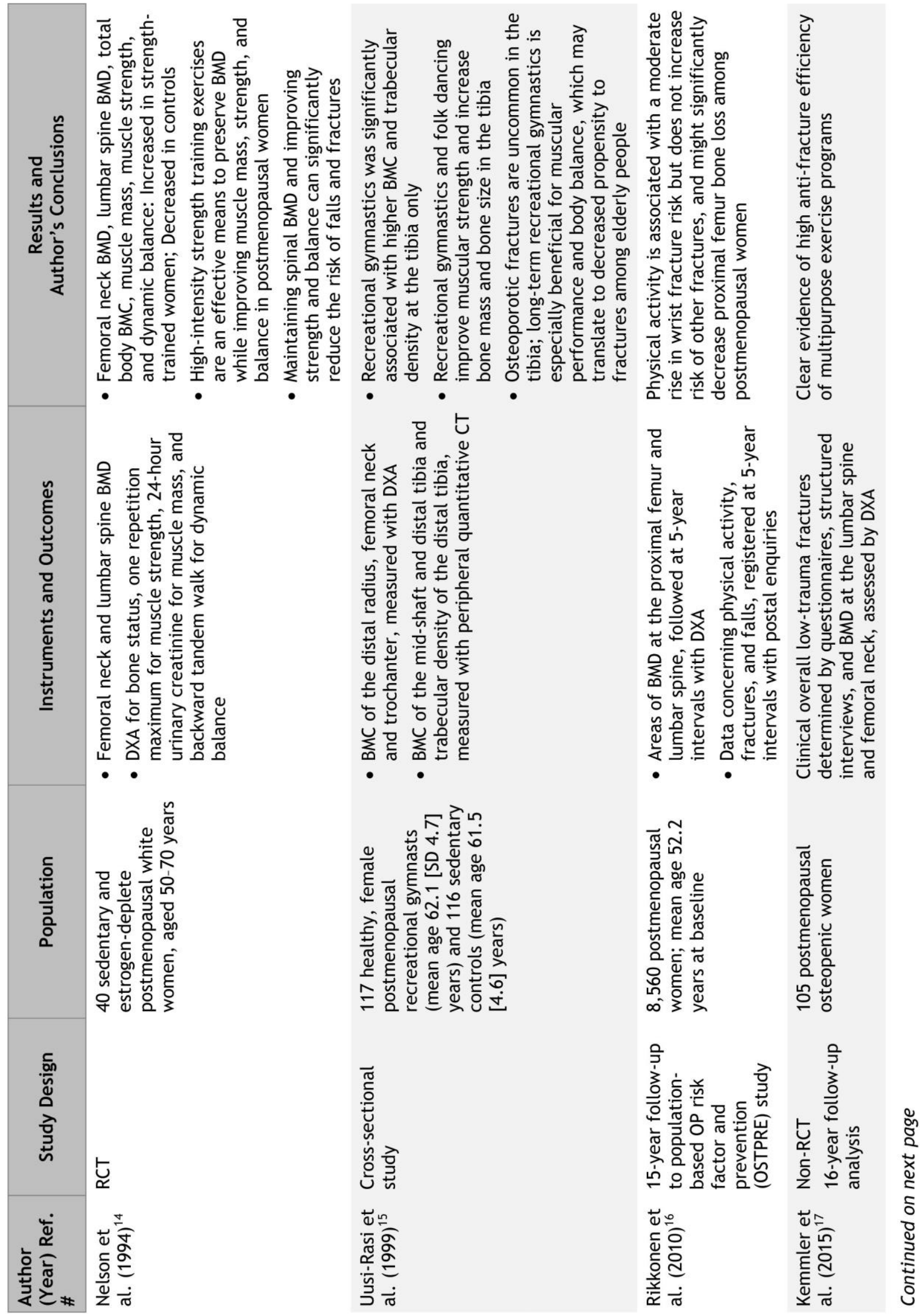




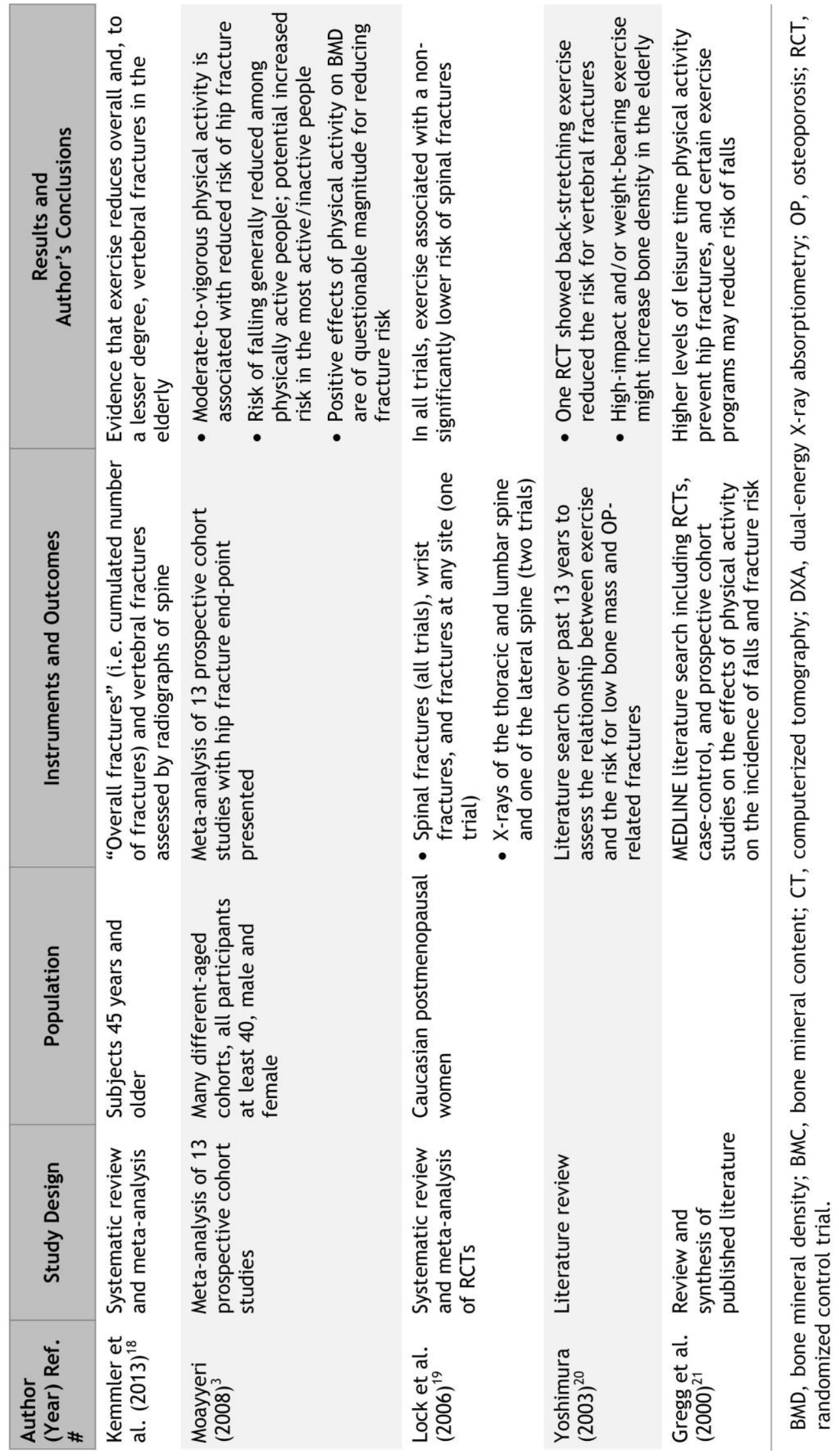


of falling and associated fractures, and diminished fear of falling. Alongside the exercise training, the patients also engaged in educational sessions on fall prevention strategies. Together, these interventions were found to have a durable effect, possibly because patients felt confident upon learning that exercise does not usually increase fractures. ${ }^{27}$

Despite the noted benefits, those who decide to engage in exercise must choose to be cautious as it is highly conditional. Although moderate or vigorous exercise was shown to have a positive relationship with muscle and peak $\mathrm{BMD},{ }^{28}$ those who are extremely inactive should not take part in such intense activities initially, because their behavior might contribute to a potentially increased risk of falls when first exercising and subsequently result in fractures. ${ }^{3}$ A low-to-moderate-intensity workout on a regular schedule was found to be the best way to deal with such situations. ${ }^{4}$ One study had also associated exercise with a mild increase in wrist fractures; ${ }^{29}$ the exact reason for this is unknown. It had not been found to increase fractures in other areas of the body.

There was not enough solid evidence about highforce exercises to strongly conclude whether they are detrimental or beneficial. However, they were not found to result in more fractures than normal 20,21 and were noted to be able to increase BMD in young women, although this might be in part due to the small population samples. The elderly, who have more frail immune systems, lower strength, and weaker regenerative capabilities compared to the younger population, would not be advised to participate in high-force activities. ${ }^{30}$ However, high impact did not translate to high intensity, which in fact greatly improved BMD and muscle strength with minimal injury. ${ }^{28}$ In addition, moderate-force activities were found to reduce risk of fractures. ${ }^{31}$ Swimming, strength training, or even walking for extended distances was found to be effective in significantly decreasing urinary deoxypyridinoline which is related to a reduction in bone resorption. $3^{2}$ The chance of falls, which may correlate to the chance of fractures, was practically non-existent, while the intensity was moderate to high. ${ }^{2}$

\section{Types of Exercise}

There was great variation in optimal exercise strategy between people, which can stem from ethnicities, background, education, health care, wealth, nutrition, and genetics. However, research indicated that certain groups of exercise were more effective at counterbalancing the effects of OP. Fractures and
BMD vary by exercise type. Osteoporosis Canada lists four different essential forms of exercise: strength training, posture training, balance training, and aerobic training.

Strength training, also known as resistance training, was the most effective. 33 The primary objective of strength training is to increase muscle mass, which is often an issue with the elderly; by age 70 people are expected to lose between $50 \%$ and $55 \%$ of their maximum muscle mass. The low muscle mass can allow for easy falls resulting in fractures that might seem impossible for another person in the same situation. Strength training may also increase BMD in certain parts of the body, including the spine and hip bone, 4,34 as was evident in one RCT of strength-trained postmenopausal women. ${ }^{14}$ As OP is a common complication that results in hip fracture following a fall, increasing BMD in the hip may prevent further fractures 35 and reduce the risk of fractures being related to OP. Improvements in spinal strength is also critical as OP is often associated with spinal disability and deformity. A RCT involving a 10-year follow-up found the incidence of vertebral compression fracture in postmenopausal women who underwent progressive, resistive, back-strengthening exercises for 2 years was only $1.6 \%$ compared to the control group, which had an incidence rate of $4.3 \% .{ }^{13}$ However, contrary to that study, a systematic review and meta-analysis of RCTs found that, during all trials, exercise only resulted in a non-significantly lower risk of spinal fractures. ${ }^{19}$ Nevertheless, the most effective type of exercise intervention on BMD for the neck of the femur is non-weight-bearing high-force exercise such as progressive resistance strength training for the lower limbs. ${ }^{10}$ Walking was also included in this category, as it made the patient work against the force of gravity. Data pointed to high levels of walking being able to reduce bone resorption in elderly women and maintain levels of quantitative ultrasound parameters. ${ }^{32}$ As walking is relatively low risk, it is highly recommended although it cannot replace other strength training exercises.

Posture training involves proper alignment and positioning of various body parts, especially the spine. Kyphosis, or an arching of the back, naturally begins to develop as people age. However, weak extensor muscles along the back can result in excessive kyphosis, which is often the cause of fractures. Although OP fractures in the spine rarely cause paralysis as fractures occur in the lower or middle area of the spine, they can cause disabilities, gradual loss 
of mobility, and death. The aim of posture training is to strengthen muscles along the back and the hip, the areas most affected by OP, and improve alignment of the spine so small twists and loads upon the vertebrae will not result in fractures.5,36 This is especially important for patients with spine fractures in order to prevent repeated fractures. Posture training includes exercises that stretch the back and stomach area. None of these exercises are highforce, as even small to moderate amounts of increased load on the back may result in fractures.

Balance training exercises are those that work to improve balance and reduce falls. A total of 20\%$30 \%$ of Canadians fall each year, 37 and, as falls are the most common trigger for fractures for patients with $\mathrm{OP}$, enhancing balance and coordination is critical in reducing fractures. ${ }^{8}$ These exercises are mostly aimed at enhancing leg muscles which allows patients to be steadier when standing up or moving. Results demonstrated greater mobility and improved functional and static balance. Long-term balance training reduced fear of falling and increased isometric strength and standing time. ${ }^{24,39}$ Balance training can be practiced anywhere.

In a RCT, 65 healthy Caucasian women were tested to study the effect of non-loading exercise on bone aging. During the 2-year study, bone loss did not vary statistically from the intervention group to the control group, ${ }^{23}$ meaning posture and balance exercises did not increase BMD and might be ineffective in reducing fracture risk in the short term. However, muscle mass increased noticeably. ${ }^{23}$ Longterm effects are different; a follow-up conducted to this study found that the difference in bone mineral density, while not significant between the two groups at baseline and 2-year follow-up, was significant at 10-year follow-up. ${ }^{13}$

Aerobic training is any physical activity that increases heart and breathing rate, and can be performed continuously for several minutes at a time. The purpose of aerobic training is to strengthen the heart and lungs, as well as other muscles within the body, and improve endurance. This specific type of exercise overlaps with the previous three. Weightbearing and resistance aerobic exercise is recommended for patients with OP, as it manages to increase both muscle mass and bone density, reducing the chance of fractures.5 Recreational gymnastics or folk dancing are also considered aerobic activities, and while they increase muscular performance they are associated with higher BMD only at the tibia. 15
According to Canada's Physical Activity Guide, all adults are encouraged to undergo at least 30 minutes of moderate to vigorous aerobic exercises 5 days a week, even for elderly with OP and previous fractures. 5 An extra hour of exercise a week for women in moderate-intensity sporting translates to a $0.8 \%$ increase in hip $\mathrm{BMD}, 40$ and a $7 \%-8 \%$ increase in peak BMD results in a $50 \%$ reduction in fracture risk. ${ }^{28}$ Although women are four times as likely to develop OP due to their smaller bone mass and longer life span compared to men, exercise should still be performed by the male population.

As there may be no single optimal exercise strategy, a multimodal exercise program incorporating many of the strategies above should be considered, as long-term follow-ups of multipurpose exercise programs usually evidence clinical lowtrauma fractures and general anti-fracture efficiency. ${ }^{17}$ One RCT combining high-velocity progressive resistance training, weight-bearing impact, and challenging balance or mobility activities resulted in significant net gains in femoral neck and lumbar spine BMD. It posits that a multimodal exercise program represents an effective approach to improving multiple musculoskeletal and functional performance measures in older, at-risk adults. ${ }^{29}$ Another study found exercise involving a combination of balance and lower-extremity strength training may reduce risk of falling. ${ }^{21}$ Further large-scale trials are needed to evaluate the efficacy of this multimodal approach on reducing falls and fractures. ${ }^{18}$

\section{Potential Barriers}

Those who have no former habit of exercise cannot hope to improve significantly upon their osteoporotic condition. High-stress and weight-bearing exercises had been shown to have a positive correlation with increase in peak bone mass, which reduces fracture risk. ${ }^{41}$ After menopause, however, research showed that bone mass density will start to decrease even under the influence of exercise..$^{2}$ Seniors with OP would be unable to make significant progress in increasing BMD, and can only reduce or prevent deterioration. Muscle mass begins to decline earlier. It is unlikely the body would remain competent at old age, even under the influence of exercise. Adults are advised to exercise regularly at moderate to vigorous intensities well into old age, to ensure that they can effectively combat or prevent the disease from developing or progressing.

Another widely noted barrier is the lack of symptoms for patients with OP. The only signs OP 
showed before a painful fracture was stooped posture, loss of height and back pain, all of which could be attributed to natural aging of the body and degenerative disc disease. Thus, OP was often undetected until a fracture occurred, by which time mobility might have become limited and recovery near impossible. Even amongst long-term care (LTC) patients, there is a $40 \%$ mortality rate within a year following a hip fracture. 43 For the remaining residents, although a certain extent of mobility could be recovered, only $40 \%$ of patients were able to return to their former living standard after the fracture,7 and at least $10 \%$ re-fractured within a year. 43 Once again, the most successful single intervention is regular exercise, which will delay or prevent the progression of OP and prevent fractures from ever occurring in the first place..$^{12}$ Occasional quantitative ultrasound screening is also recommended. ${ }^{32}$

Interestingly, one RCT concluded that only undergoing the single intervention of exercise produces results far from optimal and may have negative results. 44 It did note, however, that large-scale efforts are necessary to bring meaning to the findings. While exercises alone being insufficient had been previously documented, more trials must be carried out to validate the potential negative effects of exercise.

\section{Vitamin D and Calcium Supplementation}

While exercises are considered one of the most important methods of OP management, there are other available interventions. In particular, calcium and vitamin D supplements are often recommended to patients, as these two substances are vital in maintaining bone health and are lacking in patients with OP. Calcium builds and maintains bones, while vitamin $\mathrm{D}$ protects bones and allows the body to absorb stored calcium.45 Osteoporosis Canada recommends daily vitamin $\mathrm{D}$ supplements of 800 to 2,000 IU for adults over 50 who are at high risk of fractures, as well as those with OP or vitamin D deficiency; younger adults need at least 400 IU of vitamin D intake from supplements every day. 46 Intakes of over 2,000 IU for any age can produce a number of side effects including skin reactions, sleepiness, nausea, vomiting, and changes to blood sugar and blood pressure.47 Vitamin D deficiency or excess also impacts cardiovascular death risk and falls. $4^{8}$ Vitamin D $25 \mathrm{OH}$ Levels should be around 70 $\mathrm{nm} / \mathrm{L}$ in blood and remain in the range of 50-100 $\mathrm{nm} / \mathrm{L}$ to achieve the benefit. 49 As for calcium, which the body does not naturally produce, adults over 50 are recommended by OP Canada to have dietary supplementation equal to three servings of dairy products daily which is equivalent to $1,200 \mathrm{mg}$ of elemental $\mathrm{Ca}$, while adults under 50 should take two servings. For residents at high risk who cannot meet the dietary calcium requirement, supplements containing up to $500 \mathrm{mg}$ of elemental calcium daily is recommended. $5^{\circ}$ Like with vitamin $\mathrm{D}$, there must be strict regulations as excess calcium can cause kidney stones, fatigue, depression, and hypercalcemia. ${ }^{51}$

However, similar to exercise, vitamin D supplementation has been shown to be ineffective in reducing falls and to have a limited effect, especially when used as a single intervention..$^{2}$ While the Scientific Advisory Council of OP Canada recommend daily supplements for those at high risk of fracture, other sources claim it should not be taken without other forms of intervention. $5^{2}$ For example, vitamin $\mathrm{D}$ taken alongside calcium probably reduces hip fractures and mortality more than vitamin D alone or calcium alone. For residents at high risk, such an intervention results in an estimated 15/ 1,000 fewer hip fractures. ${ }^{53-55}$

Calcium supplementation is also ineffective when used as the primary defense against OP and fractures, and has been found to provide minor improvements to BMD, even when taken alongside vitamin D..$^{6}$ In addition, calcium supplementation and cardiovascular risk seemingly have a positive relationship. Calcium supplementation is believed to contribute to the development of cardiovascular events such as myocardial infarction, and stroke in rare scenarios, but there is limited evidence suggesting a correlation..$^{6}$ Some studies, such as a NIHAARP Diet and Health prospective study consisting of several RCTs from 2013, discovered an increased risk of cardiovascular events from calcium supplementation, which they reasoned likely arose from vascular calcification caused by the artificial intake. ${ }^{57}$ Most research, such as a 2015 meta-analysis of postmenopausal women, found no relationship. 58

Extensive evidence shows that dietary calcium, the calcium received from natural sources of food, has an inverse relationship with cardiovascular disease and other blood disorders. A meta-analysis from 2016 found a 9\% decrease in stroke risk for every $200 \mathrm{~g}$ of total fermented dairy intake per day. ${ }^{9}$ As a result, greater dietary calcium intake is encouraged over calcium supplements.

Besides being an important mineral for bone health, however, calcium aids with muscle contrac- 
tion and is in constant use when exercising. 45 To compensate for the drop in calcium levels as the body consumes it through physical activity, extra calcium from the bones is released, which can further lower BMD in patients with OP and effectively defeat the purpose of exercise. ${ }^{60}$ Further research should be devoted to determining whether exercises are best done alongside taking calcium and vitamin D supplements, and the amount that is considered tolerable, and how it relates to the well-known guidelines and existing controversies. Evidence shows that exercises increase BMD, but there could potentially be a threshold when it is instead detrimental. Only low-quality evidence is available to show that multifactorial interventions reduce risk of hip fractures (10 per 1,000 fewer: 95\% CI). ${ }^{61}$

Determining such a threshold is a critical step in ensuring that patients can optimally benefit from this intervention.

\section{Patient Management Recommendations}

Traditional management of patients with osteoporosis revolves around pharmacological treatments as well as screening. There have been few studies on pharmacological drugs in the prevention of recurring fractures, but apparently the evidence is strong enough to justify their use even though there are potential side effects. ${ }^{62}$ However, many patients with previous fractures fail to receive the proper drugs. An investigation from Belgium identified 23,146 patients who had previously sustained hip fractures and were hospitalized. Out of them, only 6\% received anti-osteoporotic pharmacological treatment. ${ }^{63}$ Thus, a priority is to ensure all patients receive the proper interventions to suit their needs.

Interventions such as exercise, vitamin $\mathrm{D}$, and calcium supplementation are disregarded to an even greater extent. ${ }^{64}$ Firstly, and most importantly, the patients must have a regular exercise program with emphasis on resistance or strength training, which has maximum benefit and a low risk of falls or fracture.10,33 Staff must continuously encourage patients to undergo the exercise, as many patients might not participate willingly. Patients should also practice balance training exercises such as Tai Chi, a Chinese martial art, which was associated with a $47.5 \%$ reduction in fall risk during a RCT. ${ }^{65}$ In addition to enhancing mobility, balance training also decreases the risk of falling and improves patients' self-perceived health. ${ }^{5}$ It does not, however, reduce the risk of fracture should a patient fall, only the occurrence of falls. ${ }^{62}$
Patients who have had vertebral compression fractures or have abnormal back structures should also be encouraged to wear thoracolumbar braces, a type of brace that attempts to straighten the spine. Rigid thoracolumbar braces forcibly hold up the spine with the goal to develop proper back structures. However, some patients dislike the lack of mobility of these rigid braces, and instead will use softer braces, such as a posture-training support brace. ${ }^{64}$ The purpose of such braces, which are essentially weights, is to constantly remind patients to straighten their mid-backs. In a pilot study, braces were found to reduce back pain among patients with acute vertebral compression fracture, with 17 out of 23 patients reporting significant improvement. ${ }^{66} \mathrm{On}$ the other hand, hip protectors, which are meant to reduce the impact of falls to the hip, are controversial. Long-term compliance is an unresolved issue, and many studies have not reported noticeable benefit. ${ }^{62}$

Patients should have regular intake of vitamin D and calcium. Since the body naturally synthesizes vitamin D upon exposure to UVB sunlight radiation, ${ }^{67}$ patients should be taken outside, with a caregiver or personal support worker (PSW), for 510 minutes of exposure at least twice a week near midday, when UVB radiation is strongest. 64 Patients should also consider taking vitamin D supplementation, in the range of 800-2,000 IU.46 If temperatures are cold or there is no option for sunlight exposure, patients should consider simply taking the supplementation. However, this is just a guideline; the quantity and exact method must be evaluated on a case-by-case basis, and interventions should only be implemented with the informed consent of the patient.

Calcium supplementation should be around three servings of dairy products daily, and can be taken in multiple forms, such as calcium citrate and calcium carbonate. $5^{\circ}$ Calcium supplementation is preferably to be taken alongside meals, as many forms only function as desired with acids. ${ }^{64}$ Similar to vitamin $\mathrm{D}$, the risks of calcium supplementation should be considered on individual basis. Generally, dietary calcium supplementation, as opposed to artificial calcium supplementation, is safer and preferred.

Other, equally important, simple but pro-active approaches exist that reduce the chance of falls. Notably, efforts should be made to reduce clutter and environmental distractions, which can affect the ease of navigation. ${ }^{62}$ In addition, use of devices that 
aid in movement, such as walkers, should also be considered depending on the patient's condition.

Long-term care facilities, in particular, must seek to incorporate daily moderate-intensity exercise sessions for patients, with emphasis on posture, balance, and strength resistance exercises. However, there must be careful evaluation of which patients can partake in these exercise sessions, as the risk of adverse events such as falls is increased for those who are most inactive. The LTC facility should obtain information regarding the prior activity levels of candidate patients, in order to restrict the participation of patients in the exercise sessions as necessary. Ideally, strict inclusion/exclusion criteria should be developed, which would enable LTC employees or PSWs to determine which patients can be recommended to undergo regular exercise and what type of intervention would be individually suitable.

Potential barriers to the integration of said exercise programs include the cost of the necessary equipment, as well as the cost of running multiple tailored exercise programs. The potential staff training requirements must be considered, and the staff must remain vigilant in their monitoring of patient progress in order to ensure that no adverse effects are being experienced. Exercise specialists such as kinesiologists, personal trainers, and physiotherapists could be used to train non-specialized LTC hospital staff initially, so that the exercise programs may remain cost-effective. One extensive systematic review found that effective group-based exercise programs can be implemented in LTC hospitals with monetary resource constraints, with the use of trained staff members (e.g. nurses, PSWs, and volunteers), using simple and inexpensive equipment, and carried out three times per week for $30-45$ minutes per session.68 More research should determine how to optimize the feasibility of exercise programs specifically targeted to the elderly population residing in different long-term settings and/or their homes, and a patient inclusion/exclusion guideline should be created.

\section{Areas of Future Research}

Osteoporosis is a "silent disease" because its symptoms are almost unrecognizable and attacks without warning. This is in part due to the lack of symptoms but also due to the limited knowledge and information regarding its risk factors, which play just as big a role in identifying diseases. Further research is needed to identify and prevent OP before it develops, knowing that exercise can only provide a mild improvement to the condition. ${ }^{11}$ If we were to have an outline and a table for the risk factors of OP, we could identify high-risk elderly individuals and, by getting them to undergo exercise, possibly prevent OP from ever causing fractures.

Furthermore, while there is evidence that exercise reduces fractures to a certain extent, publication bias may have weakened the results. More RCTs and follow-ups regarding the relationship between exercises and fractures in all prone sections of the body, with vertebral fractures as a primary endpoint, should be carried out.

\section{CONCLUSION}

Despite previous belief that exercise contributes to fractures, it has clearly been identified as a viable method for combating BMD and muscle loss and reducing falls and fractures. All seniors, including those who have a history of OP and fractures, are highly recommended to undergo daily, mediumforce training sessions with emphasis on posture, balance, and most importantly strength resistance exercises at a minimum of moderate intensity. Exercises should also be balanced into the work life of young adults to ensure BMD and muscle mass are still present into the senior years. The exact age to start is still unclear. Care and caution must be taken when exercising as injuries and fractures can still happen in the process. For this reason, high-force exercises should be considered with extreme caution: although they have been shown to have some significant positive impact, they should be avoided by all those who are inexperienced or have significantly limited strength and mobility; medium-force exercise is preferred. Exercises alone, however, are insufficient to halt the course of the disease and may have adverse side effects. The elderly are advised to undergo regular screening, as knowledge about risk factors is limited, in order for the disease to be diagnosed early, and to use multiple interventions possibly including vitamin D supplementation alongside exercise. It is uncertain how much recovery is possible after a fracture has occurred, but exercising in moderation is undoubtedly an essential step that must be taken.

\section{REFERENCES}

1. U.S. National Library of Medicine. Osteoporosis overview. Updated December 2016. Available at: http://bit.ly/2sQEYYg (accessed December 13, 2016). 
2. Ali NS, Bennett SJ. Postmenopausal women. Factors in osteoporosis preventive behaviors. J Gerontol Nurs 1992;18:23-32. Crossref

3. Moayyeri A. The association between physical activity and osteoporotic fractures: a review of the evidence and implications for future research. Ann Epidemiol 2008;18:827-35. Crossref

4. Schwab P, Klein RF. Nonpharmacological approaches to improve bone health and reduce osteoporosis. Curr Opin Rheumatol 2008;20:213-17. Crossref

5. Osteoporosis Canada. What Kind of Activity is Best. Updated 2016. Available at: http://bit.ly/2rZd4Jq (accessed April 3, 2017).

6. International Osteoporosis Foundation. Epidemiology. Updated 2015. Available at: http://bit.ly/2t8I3.5b (accessed April 3, 2017).

7. International Osteoporosis Foundation. Facts and Statistics. Updated 2015. Available at: http://bit.ly/ 2r7HtEg (accessed April 3, 2017).

8. Kristensen MT, Foss NB, Kehlet H. Timed "up \& go" test as a predictor of falls within 6 months after hip fracture surgery. Phys Ther 2007;87:24-30. Crossref

9. Osteoporosis Canada. Drug Treatments. Updated 2016. Available at: http://bit.ly/2r7BvmW (accessed March 28, 2017).

10. Howe TE, Shea B, Dawson LJ, et al. Exercise for preventing and treating osteoporosis in postmenopausal women. Cochrane Database Syst Rev 2011;(7): CDooo333. Crossref

11. Ebrahim S, Thompson PW, Baskaran V, Evans K. Randomized placebo-controlled trial of brisk walking in the prevention of postmenopausal osteoporosis. Age Ageing 1997;26:253-60. $\underline{\text { Crossref }}$

12. Preisinger E, Alacamlioglu Y, Pils K, et al. Exercise therapy for osteoporosis: results of a randomised controlled trial. Br J Sports Med 1996;30:209-12. $\underline{\text { Crossref }}$

13. Sinaki M, Itoi E, Wahner HW, et al. Stronger back muscles reduce the incidence of vertebral fractures: a prospective 10 year follow-up of postmenopausal women. Bone 2002;30:836-41. $\underline{\text { Crossref }}$

14. Nelson ME, Fiatarone MA, Morganti CM, Trice I, Greenberg RA, Evans WJ. Effects of high-intensity strength training on multiple risk factors for osteoporotic fractures: a randomized controlled trial. JAMA 1994;272:1909-14. $\underline{\text { Crossref }}$

15. Uusi-Rasi K, Sievanen H, Vuori I, et al. Long-term recreational gymnastics, estrogen use, and selected risk factors for osteoporotic fractures. $\mathrm{J}$ Bone Miner Res 1999;14:1231-8. $\underline{\text { Crossref }}$
16. Rikkonen T, Salovaara K, Sirola J, et al. Physical activity slows femoral bone loss but promotes wrist fractures in postmenopausal women: a 15-year follow-up of the OSTPRE study. J Bone Miner Res 2010;25:2332-40. Crossref

17. Kemmler W, Bebenek M, Kohl M, von Stengel S. Exercise and fractures in postmenopausal women. Final results of the controlled Erlangen Fitness and Osteoporosis Prevention Study (EFOPS). Osteoporos Int 2015;26:2491-9. $\underline{\text { Crossref }}$

18. Kemmler W, Haberle L, von Stengel S. Effects of exercise on fracture reduction in older adults: a systematic review and meta-analysis. Osteoporos Int 2013;24:1937-50. $\underline{\text { Crossref }}$

19. Lock CA, Lecouturier J, Mason JM, Dickinson HO. Lifestyle interventions to prevent osteoporotic fractures: a systematic review. Osteoporos Int 2006;17: 20-8. Crossref

20. Yoshimura N. Exercise and physical activities for the prevention of osteoporotic fractures: a review of the evidence. Nihon Eiseigaku Zasshi 2003;58:328-37. Crossref

21. Gregg EW, Pereira MA, Caspersen CJ. Physical activity, falls, and fractures among older adults: a review of the epidemiologic evidence. J Am Geriatr Soc 2000;48:883-93. $\underline{\text { Crossref }}$

22. Osteoporosis Canada. Exercise for Healthy Bones. Updated May 2012. Available at: http://bit.ly/2rj4R14 (accessed August 15, 2016).

23. Sinaki M, Wahner HW, Offord KP, Hodgson SF. Efficacy of nonloading exercises in prevention of vertebral bone loss in postmenopausal women: a controlled trial. Mayo Clin Proc 1989;64:762-9. Crossref

24. Iwamoto J, Otaka Y, Kudo K, Takeda T, Uzawa M, Hirabayashi K. Efficacy of training program for ambulatory competence in elderly women. Keio $\mathrm{J}$ Med 2004;53:85-9. $\underline{\text { Crossref }}$

25. Papaioannou A, Santesso N, Morin SN, et al. Recommendations for preventing fracture in long-term care. CMAJ 2015;187:1135-44, E450-61.

26. Papaioannou A. Recommendations for Preventing Fracture in Long-Term Care. Osteoporosis Canada website. Available at: http://bit.ly/2rZdhwc (accessed January 3, 2017).

27. Olsen CF, Bergland A. The effect of exercise and education on fear of falling in elderly women with osteoporosis and a history of vertebral fracture: results of a randomized controlled trial. Osteoporos Int 2014;25: 2017-25. $\underline{\text { Crossref }}$

28. Henderson NK, White CP, Eisman JA. The roles of exercise and fall risk reduction in the prevention of 
osteoporosis. Endocrinol Metab Clin North Am 1998; 27:369-87. Crossref

29. Gianoudis J, Bailey CA, Ebeling PR, et al. Effects of a targeted multimodal exercise program incorporating high-speed power training on falls and fracture risk factors in older adults: a community-based randomized controlled trial. J Bone Miner Res 2014;29:18291. Crossref

30. International Osteoporosis Foundation. Exercise Recommendations. Available at: http://bit.ly/2sqEz1h (accessed September 27, 2016).

31. Karlsson M. Does exercise reduce the burden of fractures? Acta Orthop Scand 2002;73:691-705. Crossref

32. Kitagawa J, Nakahara Y. Associations of daily walking steps with calcaneal ultrasound parameters and a bone resorption marker in elderly Japanese women. $\mathrm{J}$ Physiol Anthropol 2008;27:295-300. $\underline{\text { Crossref }}$

33. Shaw G. Women and Weight Training for Osteoporosis. Updated January 2009. Available at: http:// wb.md/2sgGxSi (accessed March 30, 2017).

34. Smith El, Gilligan C. Physical activity effects on bone metabolism. Calcif Tissue Int 1991;49(Suppl):S5O-4. Crossref

35. Osteoporosis Canada. After the Fracture: Information about Pain and Practical Tips for Movement. Updated 2016. Available at: http://bit.ly/2rOk1im (accessed March 30, 2017).

36. Pratelli E, Cinotti I, Pasquetti P. Rehabilitation in osteoporotic vertebral fractures. Clin Cases Miner Bone Metab 2010;7:45-7.

37. Public Health Agency of Canada. Seniors' Falls In Canada. Second Report. Updated 2014. Available at: http://bit.ly/2saptMT (accessed October 15, 2016).

38. American Academy of Orthopaedic Surgeons. Osteoporosis and Spinal Fractures. Updated January 2016. Available at: http://bit.ly/2saSMPr (accessed September 3, 2016).

39. Gusi N, Carmelo Adsuar J, Corzo H, Del Pozo-Cruz B, Olivares PR, Parraca JA. Balance training reduces fear of falling and improves dynamic balance and isometric strength in institutionalised older people: a randomised trial. J Physiother 2012;58:97-104. Crossref

40. MacInnis RJ, Cassar C, Nowson CA, et al. Determinants of bone density in 30- to 65-year-old women: a co-twin study. J Bone Miner Res 2003;18:1650-6. Crossref

41. Yoshimura N. Intervention in lifestyle factors for the prevention of osteoporosis and osteoporotic fractures. Clin Calcium 2005;15:1399-408. Japanese.
42. Maltais M, Desroches J, Dionne I. Changes in muscle mass and strength after menopause. J Musculoskelet Neuronal Interact 2009;9:186-97.

43. Lau AN, Loannidis G, Potts Y, et al. What are the beliefs, attitudes and practices of front-line staff in long-term care (LTC) facilities related to osteoporosis awareness, management and fracture prevention? BMC Geriatr 2010;10:73. $\underline{\text { Crossref }}$

44. Becker C, Rapp K. Fall prevention in nursing homes. Clin Geriatr Med 2010;26:693-704. rossref

45. National Osteoporosis Foundation. Calcium/Vitamin D. Updated 2016. Available at: http://bit.ly/2rZegws (accessed March 30, 2017).

46. Osteoporosis Canada. Vitamin D: An Important Nutrient That Protects You Against Falls and Fractures. Updated 2016. Available at: http://bit.ly/2r7LN6H (accessed March 30, 2017).

47. Mayo Clinic. The Natural Standard Research Collaboration. Drugs and Supplements Vitamin D. Updated November 2013. Available at: http:// mayocl.in/2saSGrg (accessed March 30, 2017).

48. Judd S. Vitamin D deficiency and risk for cardiovascular disease. Circulation 2008;117:503-11. Crossref

49. University of Copenhagen - The Faculty of Health and Medical Sciences. High Levels of Vitamin D Is Suspected of Increasing Mortality Rates. Updated March 2015. Available at: http://bit.ly/2sgQ5g3 (accessed October 4, 2016).

50. Osteoporosis Canada. Calcium: An Important Nutrient that Builds Stronger Bones. Updated 2016. Available at: http://bit.ly/2rZhDU9 (accessed September $28,2016)$.

51. Ruvolo-Wilkes V. Negative Side Effects of Too Much Calcium. Updated March 2011. Available at: http:// bit.ly/2rjrzpT (accessed December 20, 2016).

52. Canadian Agency for Drugs and Technologies in Health. Vitamin D Supplementation for the Prevention of Falls and Fractures in Residents in Long-Term Care Facilities: A Review of the Clinical Effectiveness, Cost-Effectiveness, or Guidelines. Updated April 2016. Available at http://bit.ly/2rONHfg (accessed December 20, 2016).

53. Bischoff-Ferrari HA, Willett WC, Orav EJ, et al. A pooled analysis of vitamin $\mathrm{D}$ dose requirements for fracture prevention. N Engl J Med 2012;367:40-9. Crossref

54. Avenell A, Gillespie WJ, Gillespie LD, O'Connell D. Vitamin D and vitamin D analogues for preventing fractures associated with involutional and postmenopausal osteoporosis. Cochrane Database Syst Rev 2009;(2):CDoo0227. $\underline{\text { Crossref }}$ 
55. Murad MH, Drake MT, Mullan RJ, et al. Clinical review. Comparative effectiveness of drug treatments to prevent fragility fractures: a systematic review and network meta-analysis. J Clin Endocrinol Metab 2012;97:1871-80. $\underline{\text { Crossref }}$

56. Bolland MJ, Grey A, Reid IR. Calcium supplements and cardiovascular risk: 5 years on. Ther Adv Drug Saf 2013;4:199-210. $\underline{\text { Crossref }}$

57. Xiao Q, Murphy RA, Houston DK, Harris TB, Chow WH, Park Y. Dietary and supplemental calcium intakes in relation to mortality. JAMA Intern Med 2013;173:639-46. $\underline{\text { Crossref }}$

58. Lewis JR, Radavelli-Bagatini S, Rejnmark L, et al. The effects of calcium supplementation on verified coronary heart disease hospitalization and death in postmenopausal women: a collaborative metaanalysis of randomized controlled trials. $\mathrm{J}$ Bone Miner Res 2015;30:165-75. Crossref

59. Goede JD, Soedamah-Muthu SS, Pan A, Gijsbers L Geleijnse JM. Dairy consumption and risk of stroke: a systematic review and updated dose-response metaanalysis of prospective cohort studies. J Am Heart Assoc 2016;5. pii:e002787. Crossref

6o. Heid M. Get 33\% Stronger Bones. Updated June 2013. Available at: http://bit.ly/2sQrcoy (accessed December 20, 2016).

61. Cameron ID, Gillespie LD, Robertson MC, et al. Interventions for preventing falls in older people in care facilities and hospitals. Cochrane Database Syst Rev 2012;12:CDo05465. Crossref
62. Ip TP, Leung J, Kung AWC. Management of osteoporosis in patients hospitalized for hip fractures. Osteoporos Int 2010;21(Suppl 4):S605-14. Crossref

63. Rabenda V, Vanoverloop J, Fabri V, et al. Low incidence of anti-osteoporosis treatment after hip fracture. J Bone Joint Surg Am 2008;90:2142-8. Crossref

64. Lin JT, Lane JM. Nonpharmacologic management of osteoporosis to minimize fracture risk. Nat Clin Pract Rheumatol 2008;4:20-5. Crossref

65. Wolf SL, Barnhart HX, Kutner NG, McNeely E, Coogler $\mathrm{C}, \mathrm{Xu} \mathrm{T}$. Reducing frailty and falls in older persons: an investigation of tai chi and computerized balance training. Atlanta FICSIT Group. Frailty and Injuries: Cooperative Studies of Intervention Techniques. J Am Geriatr Soc 1996;44:489-97. Crossref

66. Kaplan RS, Sinaki M. Posture training support: preliminary report on a series of patients with diminished symptomatic complications of osteoporosis. Mayo Clin Proc 1993;68:1171-6. Crossref

67. Holick MF. Sunlight, UV-radiation, vitamin D and skin cancer: how much sunlight do we need? Adv Exp Med Biol 2008;624:1-15.

68. Shakeel S, Newhouse I, Malik A, Heckman G. Identifying feasible physical activity programs for longterm care homes in the Ontario context. Can Geriatr J 2015;18:73-104. $\underline{\text { Crossref }}$ 